\title{
Effect of CVD process parameters on phase and chemical composition of BSCCO thin films
}

\author{
V.N. FUFLYIGIN, A.R. KAUL and S.A. POZIGUN \\ Chemistry Department, Moscow State University, 119899, Moscow V-234, Russia
}

\begin{abstract}
Superconducting BSCCO thin films were obtained with high deposition rate (about $35 \mathrm{~nm} / \mathrm{min}$ ) at temperatures of $720-810^{\circ} \mathrm{C}$ by MOCVD-technique. Characteristics of evaporation process of precursors were determined. The influence of deposition temperature and oxygen partial pressure on superconducting phase formation and chemical composition of the films was studied.
\end{abstract}

\section{Introduction.}

For recent years many studies were performed on the fabrication of thin films of high $\mathrm{T}_{\mathrm{c}}$ oxide superconductors [1-9]. Superconducting thin films have possibilities for application in submillimeter-wave and microwave devices, bolometers and cryoelectronic devices such as SQUID's.

The preparation techniques for BSCCO films reported in literature include sputtering [3], electron beam evaporation [4], laser ablation [5], pyrolysis of organic salts solutions [6] and chemical vapour deposition $[1,7,8]$. MOCVD due to an advantage in high deposition rate and possibility of coating of large surfaces is evidently more promising for fabrication of thin films on filaments or ribbons for electrotechnical application.

MOCVD of BSCCO thin films was reported by Yamane et al.[1], Zhang et al.[7], Endo et al.[8]. Nevertheless, some fundamental questions are still not clear. There are at least three superconducting phases in the $\mathrm{Bi}-\mathrm{Sr}-\mathrm{Ca}-\mathrm{Cu}$ oxide system: $\mathrm{Bi}_{2} \mathrm{Sr}_{2} \mathrm{CuO}_{\mathrm{x}}$ (2201-phase, $\mathrm{T}_{\mathrm{c}}=4 \mathrm{~K}$ ), $\mathrm{Bi}_{2} \mathrm{Sr}_{2} \mathrm{CaCu}_{2} \mathrm{O}_{\mathrm{x}}$ (2212-phase, $\left.\mathrm{T}_{\mathrm{c}}=80 \mathrm{~K}\right), \mathrm{Bi}_{2} \mathrm{Sr}_{2} \mathrm{Ca}_{2} \mathrm{Cu}_{3} \mathrm{O}_{\mathrm{x}}$ (2223-phase, $\mathrm{T}_{\mathrm{c}}=110 \mathrm{~K}$ ) [7]. All these phases are non-stoichiometric with respect both to metals and oxygen content; critical parameters essentially depend on phase stoichiometry. Five component phase diagram of $\mathrm{Bi}-\mathrm{Sr}$-Ca-Cu-O system is not completely studied, this fact does not allow to predict phase relations under $\mathrm{Po}_{2}-\mathrm{T}$ conditions of CVD process. Moreover the process of deposition is strongly incongruent and deviation of film composition from that of vapour depends on used $\mathrm{Po}_{2}-\mathrm{T}$ conditions. Typical deposition rates did not exceed $10 \mathrm{~nm} / \mathrm{min}$ [9] what is probably due to slow kinetics of HTSC-phase formation at generally used deposition temperature of $800^{\circ} \mathrm{C}$. More rapid deposition is desirable for practical applications. These considerations stress the necessity of process parameters optimization at high deposition rate what is the goal of this paper. 


\section{Experimental.}

BSCCO films were prepared in vertical hot-wall reactor with sharp temperature gradient furnace. Source materials (bismuth triphenyl $\mathrm{BiPh}_{3}$ and 2,2,6,6-tetramethylheptandionates-3,5 of copper $\mathrm{Cu}$ (thd) $)_{2}$, strontium $\mathrm{Sr}(\text { thd })_{2}$ and calcium $\mathrm{Ca}$ (thd $)_{2}$ ) were placed in separated evaporators. Temperatures of sources were $110-115^{\circ} \mathrm{C}$ for $\mathrm{BiPh}_{3}, 130-135^{\circ} \mathrm{C}$ for $\mathrm{Cu}(\text { thd })_{2}, 235-240^{\circ} \mathrm{C}$ for $\mathrm{Sr}(\text { thd })_{2}$ and $185-195^{\circ} \mathrm{C}$ for $\mathrm{Ca}(\text { thd })_{2}$. Vapours of precursors were transported by Ar-gas flow to reactor inlet where mixing with oxygen took place. Total argon flow was in the range of 30-69 lph, oxygen flow was 1-40 1ph. Deposition was carried out at overall pressure of 10-15 torr and temperature varied from $720^{\circ} \mathrm{C}$ to $810^{\circ} \mathrm{C}$. Deposition rate was about $35 \mathrm{~nm} / \mathrm{min}$; single crystalline (001) $\mathrm{MgO}$ was used as a substrate. After deposition cooling in oxygen flow $(0.5 \mathrm{~h})$ was created. Thickness of the films measured with Tally Step profilometer was about $1 \mu \mathrm{m}$. Films composition was determined by electron-probe microanalysis. X-ray characterization was made using Stadi P ("Stoe") diffractometer. Measurements of electrical resistance were carried out by ac four-probe technique.

\section{Results and discussion.}

3.1.Evaporation of precursors. The problem of temporal stability of precursors at evaporation temperature is well known for $\mathrm{Ba}$ (thd) $)_{2}$ [10]. This problem is also suspected to be important for $\mathrm{Ca}(\text { thd })_{2}$ and for $\mathrm{Sr}(\text { thd })_{2}$. The latter being the least volatile compound among the precursors used for BSCCO system limits the deposition rate. Thus it is important to establish the upper temperature limit of stable $\mathrm{Sr}(\text { thd })_{2}$ evaporation.

Kinetics curves of $\mathrm{Sr}$ (thd $)_{2}$ and $\mathrm{Ca}$ (thd $)_{2}$ evaporation at different temperatures and at constant carrier-gas flow are given on Fig.1. These data show that the isothermal evaporation rate of $\mathrm{Sr}(\mathrm{thd})_{2}$ is practically constant during two hours ( fourfold more than real time of deposition run) in the temperature range of $225-240^{\circ} \mathrm{C}$. At higher temperature $\left(245^{\circ} \mathrm{C}\right)$ appreciable decrease of evaporation rate was observed. Thus maximal constant evaporation rate of $\mathrm{Sr}(\mathrm{thd})_{2}(0.01 \mathrm{mmol} / \mathrm{min})$ can be achieved at $240^{\circ} \mathrm{C}$. $\mathrm{Ca}(\text { thd })_{2}$ is rather stable within all used temperature range.


Fig.1.- Temporal dependences of evaporation rate at different temperatures for $\operatorname{Sr}(\text { thd })_{2}$ (a), $\mathrm{Ca}(\text { thd })_{2}$ (b) 
Linear dependence of evaporation rate on flow rate assumes that flows were saturated with vapours of precursors. On this basis vapour density of used substances was determined. Values of enthalpy of evaporation derived from the relationship between vapour density and temperature are included in the Table 1. Value of enthalpy of evaporation calculated for $\mathrm{Cu}$ (thd $)_{2}$ is in good agreement with that known from [11] $(111.73 \mathrm{~kJ} / \mathrm{mol})$.

Table 1.

Dependences of vapour density $(\mathrm{P}, \mathrm{Pa})$ on temperature $(\mathrm{lgP}=\mathrm{A}-\mathrm{B} / \mathrm{T})$,

enthalpy of evaporation for used precursors.

\begin{tabular}{|l|c|c|c|c|}
\hline Substance & A & B & $\begin{array}{l}\text { Enthalpy, } \\
\text { kJ/mol }\end{array}$ & $\begin{array}{l}\text { Temperature } \\
\text { range, K }\end{array}$ \\
\hline $\mathrm{Cu}(\text { thd })_{2}$ & $11.5(0.3)$ & $6010(50)$ & 115 & $398-413$ \\
$\mathrm{Sr}(\text { thd })_{2}$ & $16.3(0.4)$ & $9100(55)$ & 174 & $493-513$ \\
$\mathrm{Ca}(\text { thd })_{2}$ & $16.2(0.3)$ & $8500(40)$ & 163 & $453-483$ \\
$\mathrm{BiPh}_{3}$ & $10.5(0.3)$ & $5090(30)$ & 97 & $373-393$ \\
\hline
\end{tabular}

3.2.Deposition of BSCCO films . As it was mentioned above the stoichiometry of the films essentially depends on $\mathrm{Po}_{2}-\mathrm{T}$ conditions of the deposition. It was demonstrated in our experiments that an increase of temperature results in impoverishing of the film with copper and enriching with bismuth in ratio to the sum of strontium and calcium (Fig.2). The influence of partial pressure of oxygen on the stoichiometry of film is considerably less than those of temperature, nevertheless with increasing of oxygen content in the flow the content of bismuth in film also increases (Fig.3). At the same time the content of other components is rather constant. A decrease in copper content can be assigned to the predeposition of $\mathrm{Cu}$ (thd) $)_{2}$. One could make the same explanation for bismuth: the reason for the increase of the bismuth content is the impoverishing of the film with calcium and strontium. However the fact that bismuth content depends on the partial pressure of oxygen allowsto make conclusion that the deposition of bismuth from triphenylbismuth is kinetically controlled.

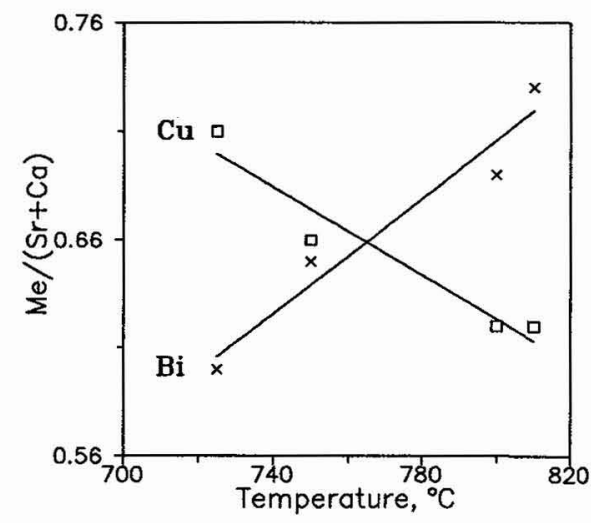

Fig.2.- Dependence of film stoichiometry on temperature.

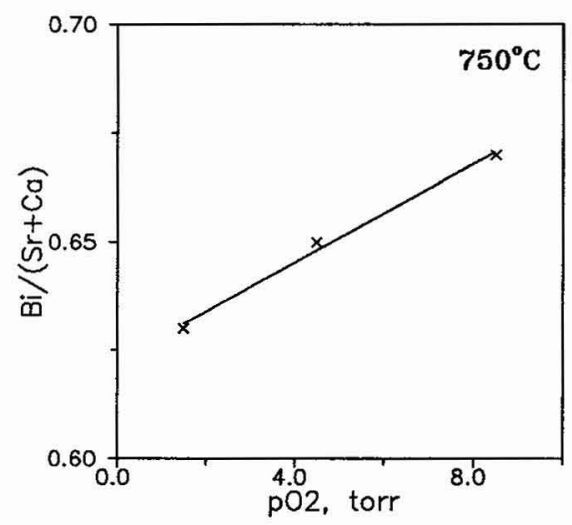

Fig.3.- Bismuth content in the films at different partial pressure of oxygen. 
Previously [6-9] the choice of $\mathrm{Po}_{2}-\mathrm{T}$ conditions of BSCCO thin films CVD process was not well substantiated. That is mainly due to the absence of reliable $\mathrm{Po}_{2}-\mathrm{T}$ diagrams of both 2212 and 2223 phases. For example, one can compare data given by Bloom [12] and Mozhaev [13]. According to the first diagram conditions of our preliminary experiments $\left(\mathrm{Po}_{2}=2 \mathrm{torr}, 800^{\circ} \mathrm{C}\right)$ correspond to the field of 2212 phase existence, but according to diagram [13] these conditions fit to the boundary between 2212 single phase field and the field corresponding to products of peritectic decomposition of this phase. As it was demonstrated by $\mathrm{X}$-ray diffraction the films obtained under conditions mentioned above did not contain any 2212 phase, the predominant phase was $\mathrm{Bi}_{2.2}+\mathrm{x}^{\mathrm{Sr}} 1.8-\mathrm{z} \mathrm{Ca}_{\mathrm{z}} \mathrm{CuO}_{\mathrm{y}}(\mathrm{Raveau}$ phase. It is evident that peritectic decomposition of 2212 phase took place at these $\mathrm{Po}_{2}-\mathrm{T}$ conditions. The temperature of 2212 phase peritectic decomposition calculated for oxygen partial pressure 2 torr from data [13] is $798^{\circ} \mathrm{C}$ what is in good agreement with our experiments. Thus partial pressure of oxygen higher than 2 torr at $800^{\circ} \mathrm{C}$ or temperature lower than $800^{\circ} \mathrm{C}$ at this $\mathrm{Po}_{2}$ are needed to meet the conditions of 2212 phase formation.



Fig.4.- X-ray diffraction patterns for the BSCCO films prepared under different conditions. A$\mathrm{Bi}_{2.18} \mathrm{Sr}_{2} \mathrm{Ca}_{0.89} \mathrm{Cu}_{2.15} \mathrm{O}_{\mathrm{X}}, \quad \mathrm{T}_{\mathrm{d}}=750_{\mathrm{o}} \mathrm{C} ; \quad \mathrm{B}-\quad \mathrm{Bi}_{2.2} \mathrm{Sr}_{2} \mathrm{Ca}_{0.92} \mathrm{Cu}_{2.21} \mathrm{O}_{\mathrm{X}}, \quad \mathrm{T}_{\mathrm{d}}=795^{\circ} \mathrm{C} ; \quad \mathrm{C}-$ $\mathrm{Bi}_{2.19} \mathrm{Sr}_{2} \mathrm{Ca}_{0.93} \mathrm{Cu}_{2.17} \mathrm{O}_{\mathrm{x}}, \mathrm{T}_{\mathrm{d}}=795^{\circ} \mathrm{C}$, in situ annealing; $\mathrm{D}-\mathrm{Bi}_{2.2} \mathrm{Sr}_{2} \mathrm{Ca}_{0.95} \mathrm{Cu}_{2.15^{\circ}} \mathrm{O}_{\mathrm{x}}$, $\mathrm{T}_{\mathrm{d}}=810^{\circ} \mathrm{C}$. -2212 phase.

The phase and chemical composition of samples obtained at different temperatures and under $\mathrm{Po}_{2}=9$ torr are given on the Fig 4. It is to be noted that according to data [13] at $\mathrm{Po}_{2}=9$ torr 2212 phase is stable up to $838^{\circ} \mathrm{C}$ that is the upper temperature limit of deposition. In addition to the strong 
temperature effect on chemical composition of the film temperature of deposition influenced strongly the kinetics of 2212 phase formation. Kinetic effect can be seen from Fig. 4 where the data for only near stoichiometric 2212 films are presented. Films obtained at the temperatures lower than $750^{\circ} \mathrm{C}$ did not contain any 2212 phase. Appreciable amount of superconducting phase was found only in the samples prepared at higher temperatures. Though all films obtained at $\mathrm{T}_{\mathrm{d}}$ lower than $795^{\circ} \mathrm{C}$ contained 2212 phase they were non-superconducting what is probably a result of lack of percolation among isolated superconducting particles. Only onset of superconducting transition at $30 \mathrm{~K}$ was observed in the case of $\mathrm{T}_{\mathbf{d}}=795^{\circ} \mathrm{C}$ (Fig.5).

We suppose this fact may be due to high deposition rate. As a result of it the time of the experiment was not sufficient for 2212 phase formation. There are several ways to solve this problem: post-annealing of deposited films, increase of substrate temperature, activation of CVD process by UVlight or plasma. We tried to use in situ annealing of films: during the process, the period of deposition (4 min) alternated with period of annealing $(1 \mathrm{~min})$ by switching vapours flow to by-pass line. Films obtained by means of such process at $795^{\circ} \mathrm{C}$ exhibited superconducting transition at $\mathrm{T}_{\text {onset }}=94 \mathrm{~K}$ and $\mathrm{T}_{\text {end }}=32 \mathrm{~K}$ with semiconductor-like $\mathrm{R}(\mathrm{T})$ dependence (Fig5).

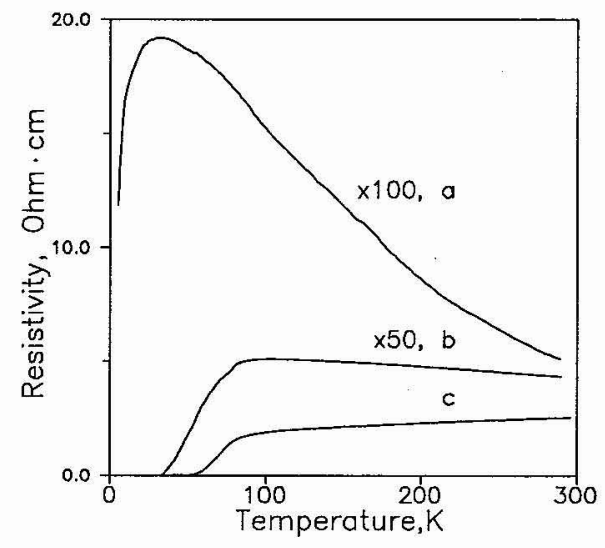

Fig.5.- Four probe electrical resistivity data for BSCCO thin films. A- $T_{d}=795^{\circ} \mathrm{C}$; B$\mathrm{T}_{\mathrm{d}}=795^{\circ} \mathrm{C}$, in situ annealing; $\mathrm{C}-\mathrm{T}_{\mathrm{d}}=810^{\circ} \mathrm{C}$.

Increase of deposition temperature to $810^{\circ} \mathrm{C}$ led to obtaining of near stoichiometric superconducting films with $\mathrm{T}_{\text {onset }}=94 \mathrm{~K}$ and $\mathrm{T}_{\text {end }}=50 \mathrm{~K}$ and having metalic resistance behavior (Fig. 5). X-ray diffraction pattern revealed the presence of 2212 phase with only traces of 2201 phase. The well pronounced texture of $00 l$-type was characteristic for the film thus obtained (Fig.4).

\section{Conclusions.}

The evaporation of $\mathrm{Sr}(\text { thd })_{2}$ and $\mathrm{Ca}$ (thd $)_{2}$ was studied and found to be rather stable during deposition and at typical temperatures of evaporators. The problem of $\operatorname{Sr}(\text { thd })_{2}$ stability arises only if 
evaporation temperature exceeds $240^{\circ} \mathrm{C}$. The highest rate of deposition about $35 \mathrm{~nm} / \mathrm{min}$ may be reached if temperature of $\mathrm{Sr}$-source is $240^{\circ} \mathrm{C}$. Temperature dependences of vapour densities for used precursors were determined to facilitate compositional monitoring of vapour phase. Strong effect of deposition temperature and $\mathrm{Po}_{2}$ on chemical composition of the films was revealed. It was found that at temperature lower than $810^{\circ} \mathrm{C}$ the rate of HTSC-phase formation is much slower than deposition rate. As a result at high deposition rate the superconducting $\mathrm{BSCCO}$ films were ontained only at $810^{\circ} \mathrm{C}$ or using in-situ annealing procedure.

\section{References.}

[1].YAMANE H., KUROSAWA H., HIRAI T. et al., Japan.J.Appl.Phys. 27 (1988) 1945.

[2].GORBENKO O.Yu., KAUL A.R., TRETYAKOV Yu.D. et al., Physica C 190 (1991) 180.

[3].KANG J.H., KAMPWIRTH R.T., GRAY K.E. et al., Phys.Lett. A 128 (1988) 102.

[4].NAKAO M., KUWAHARA H., YUASA R. et al., Japan.J.Appl.Phys. 27 (1988) L378.

[5].YEH J.-J., HONG M., Appl.Phys.Lett. 54 (1989) 769.

[6].FUKUTUMI M., MASHIDA J., TANAKA Y. et al., Japa n.J.Appl.Phys. 27 (1988) L1484.

[7].ZHANG J., ZHAO J., MARCY H.O. et al., Appl.Phys.Lett. 54 (1989) 1166.

[8].ENDO K., HAYASHIDA S., ISHIAI J. et al., Japan.J.Appl.Phys. 29 (1990) 294.

[9].NISHIKAWA T., SATOH M., ASADA K., et al., Japan.J.Appl.Phys. 31 (1992) L1592.

[10].WAHL G., SCHMADERER F., HUBER R. et al., Proc. of Int. Workshop on Chemistry and Technology of HTSC, Moscow 1 (1991) 47.

[11].IGUMENOV I.K., Stroenie, svojstva i primenenie ß-diketonatov metallov, Moscow, "Nauka" (1991) 108 (Russian).

[12].BLOOM I., FROMMELT J.M., HASH M.C. et al., Mat.Res.Bull. 26 (1991) 1269.

[13].MOZHAEV A.P., BADUN Yu.V. et al., Proc. of Int. Workshop on Chemistry and Technology of HTSC, Moscow 2 (1991) 405. 